\title{
Adaptación de Inóculos Durante el Arranque de la Digestión Anaerobia con Residuos Sólidos Orgánicos
}

\author{
Mydory Nakasima-López ${ }^{(1)}$, Paul Taboada-González ${ }^{(1) \star}$, Quetzalli Aguilar-Virgen ${ }^{(1)}$ y \\ Nicolás Velázquez-Limón ${ }^{(2)}$ \\ (1) Universidad Autónoma de Baja California, Facultad de Ciencias Químicas e Ingeniería, \\ Calzada Universidad No. 14418, Mesa de Otay, C.P. 22390, Tijuana, Baja California, México \\ (e-mail: nakasima.mydory@uabc.edu.mx; ptaboada@uabc.edu.mx; qaguilar@uabc.edu.mx) \\ (2) Universidad Autónoma de Baja California, Instituto de Ingeniería, Calle de la Normal S/N y Blvd. Benito \\ Juárez, Col. Insurgentes Este, C.P. 21100, Mexicali, Baja California, México. \\ (e-mail: nicolas.velazquez@uabc.edu.mx)
}

${ }^{*}$ Autor a quien debe ser dirigida la correspondencia

Recibido Jul. 13, 2016; Aceptado Sep. 9, 2016; Versión final Oct. 15, 2016, Publicado Feb. 2017

\begin{abstract}
Resumen
En este estudio se analizó la adaptación de dos inóculos, tomados en una industria láctea y una industria cervecera, en digestores anaeróbicos de mezcla completa (CSTR). El estudio es necesario porque en el uso de la tecnología anaeróbica, el arranque del sistema es crítico y lento, y para acelerar el tiempo de arranque de un digestor anaeróbico, se recurre a la inoculación. Se caracterizaron los residuos de alimentos y los inóculos, se alimentaron los digestores a una misma concentración y composición del residuo orgánico, y se analizó la reacción de degradación durante 150 días. La adaptación del inóculo dos (industria cervecera) al residuo orgánico fue más rápida y estable en el proceso de degradación, lo que dio un mayor rendimiento de biogás y concentración de metano (48.3\%). Sistemas de digestión operando con un $\mathrm{pH}$ por debajo de 6.5 producen biogás con bajo contenido de metano.
\end{abstract}

Palabras clave: biogás; CSTR; digestión anaeróbica; inóculos; arranque

\section{Inoculum Adaptation During Start-up of Anaerobic Digestion of Organic Solid Waste}

\begin{abstract}
In this study, the adaptation of two inoculums, taken from a dairy industry and a brewing industry, in continuous anaerobic flow stirred digesters (CSTR) was analyzed. The study is needed because in the use of anaerobic technology, the start-up of the system is critical and slow and inoculation is used to speed up the start-up time in anaerobic digesters. The food waste and inoculums were characterized, the digesters were fed at the same concentration and composition of organic waste, and degradation reaction was analyzed during 150 days. The adaptation inoculum two (brewing industry) to the organic residue was faster and more stable in the degradation process, resulting in a higher yield of biogas and methane concentration $(48.3 \%)$. Digestion systems operating with a pH below 6.5 produce biogas with low methane content.
\end{abstract}

Keywords: biogas; CSTR; anaerobic digestion; inoculums; start up 


\section{INTRODUCCIÓN}

Debido al rápido crecimiento de la población, se ha incrementado el consumo de bienes y servicios y con ello la generación de residuos. La descomposición de los residuos sólidos orgánicos (restos de alimentos y poda de jardín, principalmente) en los rellenos sanitarios, provocan graves problemas de contaminación ambiental y constituyen un recurso desaprovechado, debido a que contienen una alta fracción orgánica que puede ser empleada como fuente de energía (Fisgativa et al., 2016; Aguilar-Virgen et al., 2011). La digestión anaeróbica de los residuos orgánicos es una opción de tratamiento efectiva, ya que reduce significativamente la cantidad de residuos destinados a la eliminación y genera productos de valor, tales como la energía en forma de biogás y lodo digerido rico en nutrientes (Lohri et al., 2013). Cervi et al., (2011) indican que con la digestión anaerobia se obtienen subproductos como el bio-abono líquido y sólido, que pueden sustituir a los fertilizantes de origen sintéticos.

El funcionamiento de los digestores anaeróbicos consta de dos etapas fundamentales: el arranque y operación del sistema. El arranque es el proceso en el cual se adaptan los microorganismos anaeróbicos a las condiciones de operación del digestor ( $\mathrm{pH}$, temperatura, ambiente anaeróbico) y a las características del sustrato. La operación consiste en mantener tales condiciones para evitar la inhibición de los microorganismos, reflejada en el rendimiento del digestor (Niu et al., 2015). El arranque constituye la etapa crítica del proceso de digestión debido a que es lento y depende de una variedad de factores. Entre ellos se encuentran la temperatura, la velocidad de carga orgánica (VCO), el tiempo de retención hidráulico (TRH), el tipo de digestor, el sustrato empleado, entre otros (Ghanimeh et al., 2012; Pandey et al., 2010). Cooney et al. (2016) mencionaron que establecer una población de bacterias anaeróbicas equilibrada durante la fase de arranque es crítico y difícil.

El uso de inoculantes microbianos en el proceso de digestión anaerobia, permite que los períodos de obtención de metano sean menores, optimizando así el proceso e incrementando la producción de metano (Varnero et al., 2014). La inoculación consiste en agregar microrganismos degradadores (inóculo), provenientes de un tratamiento anaerobio estabilizado, al sustrato contenido en el digestor. Estos microrganismos se mantienen en un ambiente controlado (biológico, químico y físico) que les permite ajustarse al tipo de sustrato empleado y alcanzar un estado de equilibrio. Cuando esto sucede, se puede iniciar la operación del digestor.

Como consecuencia tanto del aumento de los precios de la energía no renovables y de la necesidad de limitar las emisiones de dióxido de carbono en la atmósfera, cada vez más países promueven el desarrollo de sistemas de energía renovable como la digestión anaerobia (Brambilla et al., 2012). En la ciudad de Mexicali, Baja California se está estudiando la posibilidad de construir digestores para tratar los residuos de alimentos de hogares y aprovechar el remanente energético. Se tienen dos posibles fuentes de inóculos: una industria cervecera y una industria láctea. Estas empresas han utilizado la digestión anaerobia con fines anti-contaminación, por lo que se desconoce si los inóculos pudieran ser adecuados para tratar residuos de alimentos. Por lo expuesto, el objetivo de este estudio fue analizar la adaptación de dos inóculos provenientes de dos industrias locales -una láctea y otra cervecera- bajo las mismas condiciones de operación, utilizando digestores anaeróbicos de mezcla completa (CSTR) y residuos de alimentos (sin codigestión o adición de sustancias alcalinas) como sustrato.

\section{METODOLOGÍA}

Se describe la caracterización del inóculo y de la materia prima fermentable. Luego se explica el sistema de digestión y la medición de los parámetros necesarios en este estudio.

\section{Caracterización de los inóculos}

Se utilizaron dos tipos de inóculos extraídos de dos digestores anaeróbicos que operan en condiciones mesofílicas $\left(35^{\circ} \mathrm{C}\right)$. El primero se obtuvo de una industria láctea (inóculo 1) y el segundo de una cervecera (inóculo 2), ambas localizadas en Tecate, Baja California, México. El digestor de la industria láctea es de tipo laguna anaeróbica, mientras que el de la industria cervecera es tipo UASB. Ambos tienen calentador integrado y operan en condiciones mesofílicas. El primer digestor emplea las aguas residuales de la propia empresa mientras que el segundo trata las aguas residuales de la empresa más las aguas residuales de un sector de la ciudad. Los inóculos fueron almacenados en dos bidones de plástico de $200 \mathrm{~L}$, por dos días a temperatura ambiente de $36^{\circ} \mathrm{C}$ aproximadamente. Para conocer el estado inicial de los inóculos antes de su uso en los digestores, se realizaron análisis físico-químicos. Los parámetros analizados fueron pH, sólidos totales (ST), sólidos totales volátiles (SV), sólidos totales fijos (SF), demanda química de oxígeno (DQO) y relación carbono/nitrógeno $(\mathrm{C} / \mathrm{N})$. Cada parámetro se evaluó de acuerdo con las normas correspondientes, que se muestran en la Tabla 1. 
Tabla 1: Métodos empleados para análisis físico-químicos de los inóculos

\begin{tabular}{|l|l|}
\hline \multicolumn{1}{|c|}{ Parámetro } & Métodos de Análisis \\
\cline { 1 - 2 } $\mathrm{pH}$ & $\begin{array}{l}\text { (SCFI Secretaría de Comercio y Fomento } \\
\text { Industrial, 1992c) }\end{array}$ \\
\cline { 1 - 2 } Sólidos Volátiles \% & (Montes-Carmona, 2008) \\
\cline { 1 - 2 } Sólidos Totales (mg/L) & $\begin{array}{l}\text { (SCFI Secretaría de Comercio y Fomento } \\
\text { Industrial, 2001b) }\end{array}$ \\
\cline { 1 - 2 } Sólidos Totales Volátiles (mg/L) & $\begin{array}{l}\text { (Hach Method 8000, 2003; SCFI Secretaría de } \\
\text { Comercio y Fomento Industrial, 2001a) }\end{array}$ \\
\cline { 1 - 2 } Sólidos Totales Fijos (mg/L) & $\begin{array}{l}\text { (Hach Method 10072, 2003.; Hach Method } \\
10128,2003 . ; \text { SCFI Secretaría de Comercio y } \\
\text { Demanda Química de Oxígeno (mg/o Industrial, 1992b, 2010) }\end{array}$ \\
\cline { 1 - 2 } Relación C/N &
\end{tabular}

\section{Caracterización y preparación del sustrato}

Considerando que se desea utilizar como sustrato los residuos orgánicos provenientes de hogares, se tomó una muestra de los residuos de una familia de 4 personas que viven en Mexicali, Baja California, durante 3 semanas consecutivas. La familia se seleccionó considerando las características de composición familiar promedio en el Estado de Baja California, indicadas por el Instituto Nacional de Estadística y Geografía (INEGI, 2015). Los residuos recolectados se transportaron al laboratorio, donde fueron separados en orgánicos e inorgánicos. Los residuos de alimentos fueron pesados en una balanza AND HP-12K, con capacidad para $12 \mathrm{~kg}$ y una sensibilidad de $0.1 \mathrm{~g}$. Posteriormente se clasificaron y pre-trataron mecánicamente, sin dilución, con un Molino Pulverizador ABC P250 de 5HP @ 220v, 3600 rpm y malla de 1 $\mathrm{mm}$. Los únicos residuos que se retiraron fueron los huesos de res, ya que por su tamaño y dureza provocaban atascamiento en la entrada del pulverizador. Debido a la potencia del pulverizador, no se presentaron problemas en la molienda del resto de los residuos.

La mezcla obtenida fue almacenada herméticamente durante 150 días en un equipo de refrigeración Dometic RGE-400, a menos de $10^{\circ} \mathrm{C}$ para evitar su fermentación (Montes-Carmona, 2008). De esta mezcla se tomaron muestras para la caracterización y alimentación de los digestores. Para conocer el estado inicial del sustrato, se tomaron muestras para realizar la caracterización físico-química y la preparación del sustrato de alimentación. Los parámetros analizados y los métodos empleados se presentan en la Tabla 2.

Tabla 2: Análisis físico-químicos del sustrato de alimentación

\begin{tabular}{|c|c|}
\hline Parámetro & Métodos de análisis \\
\hline $\mathrm{pH}$ & (SCFI Secretaría de Comercio y Fomento Industrial, 1992c) \\
\hline Densidad (g/L) & $\begin{array}{l}\text { (SEMARNAT Secretaria de Medio Ambiente y Recursos } \\
\text { Naturales, 2000) }\end{array}$ \\
\hline Humedad \% & (SCFI Secretaría de Comercio y Fomento Industrial, 1992a) \\
\hline Cenizas \% & \multirow{2}{*}{ (Montes-Carmona, 2008) } \\
\hline Sólidos Volátiles \% & \\
\hline Sólidos Totales (mg/L) & \multirow{3}{*}{ (SCFI Secretaría de Comercio y Fomento Industrial, 2001b) } \\
\hline Sólidos Totales Volátiles (mg/L) & \\
\hline Sólidos Totales Fijos (mg/L) & \\
\hline Demanda Química de Oxígeno (mg/L) & $\begin{array}{l}\text { (Hach Method 8000, 2003; SCFI Secretaría de Comercio y } \\
\text { Fomento Industrial, 2001a) }\end{array}$ \\
\hline Relación C/N & $\begin{array}{l}\text { (Hach Method } 10072 \text {, n.d.; Hach Method 10128, n.d.; SCFI } \\
\text { Secretaría de Comercio y Fomento Industrial, 1992b, 2010) }\end{array}$ \\
\hline
\end{tabular}

Para realizar la preparación del sustrato, se definió una concentración recomendada por Browne y Murphy (2014), menor al 10\% de SV en base al contenido de sólidos totales, comúnmente utilizado para digestores CSTR. En este estudio se tomó la decisión de iniciar con 7\% de SV por considerar que condiciones de baja carga pueden resultar en un crecimiento prolífico de bacterias que consumen ácido en el reactor de fermentación, lo que provoca un aumento en el pH (Grimberg et al., 2015) y que una sobrecarga orgánica provocaría una caída de pH e inhibición de la reacción (Latif et al., 2015, Yang et al., 2015; Zhang et al., 
2014), lo que se refleja en una producción de biogás mínima o nula. Zhai et al., (2015) indican que el rango óptimo de pH para la producción de metano es de 6.5-7.5, pero que el valor de pH óptimo varía con diferentes sustratos y técnicas de digestión.

\section{Sistema de digestión}

Para el estudio, se emplearon dos digestores Lambda Minifor ${ }^{\circledR}$. Los digestores están hechos de vidrio Pyrex $^{\circledR}$, de una altura de $60 \mathrm{~cm}$ y un diámetro de $37 \mathrm{~cm}$. Tienen entrada para el sustrato, salida del efluente tratado y salida del biogás por la parte superior. Cuentan con sistema de agitación de 0 a $20 \mathrm{HZ} @$ 0-120 rpm, sistema de control de temperatura de 0 a $40^{\circ} \mathrm{C}$, sensor de pH/temperatura Lambda LA801 0-13 $0 \pm$ $0.02 \mathrm{pH}$ y sensor de oxígeno disuelto Lambda $800097,0-25 \mathrm{mg} / \mathrm{mL}$ con sensibilidad de $0.1 \mathrm{mg} / \mathrm{mL}$. El volumen de trabajo es hasta 7 litros (ver Figura 1).

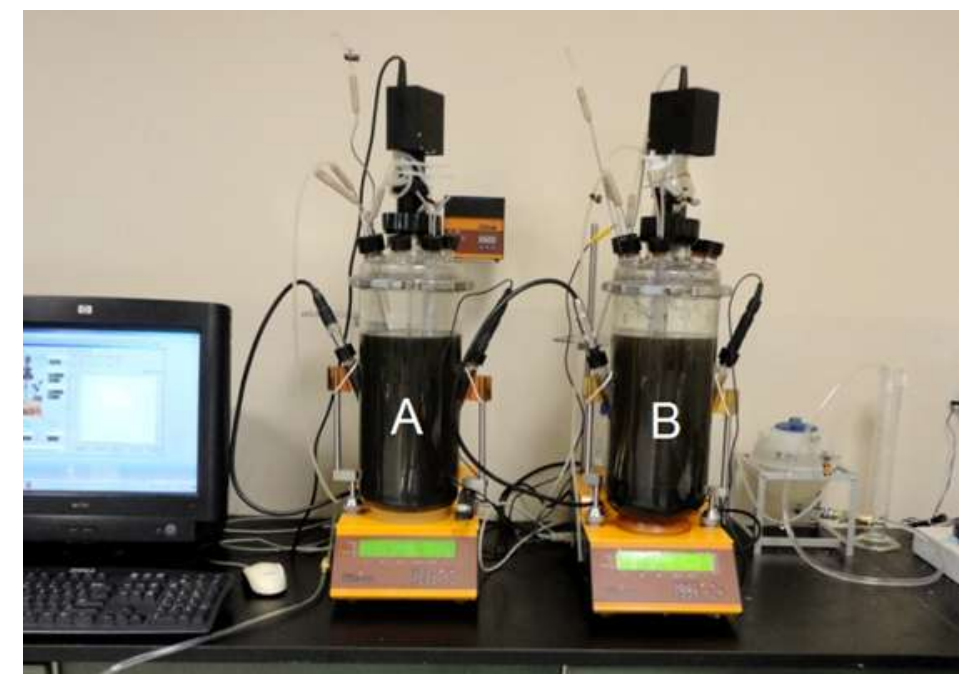

Fig. 1: Digestores anaeróbicos CSTR a escala laboratorio. A: Inóculo1, B: Inóculo 2

Se agregaron $5 \mathrm{~L}$ de inóculo a cada digestor, correspondiente al $70 \%$ de la capacidad total del digestor (volúmen útil), y se dejaron reposar por 10 días, dando agitación 3 veces por día durante cinco minutos, a una velocidad de 48 a $60 \mathrm{rpm}$. Durante este periodo no se agregó sustrato al digestor, solamente se revisó la temperatura y $\mathrm{pH}$ para determinar la adecuación de los microorganismos al sistema. La temperatura de operación se mantuvo a $35 \pm 2{ }^{\circ} \mathrm{C}$ durante todo el estudio. Una vez que el pH del inóculo se estabilizó en los digestores, se agregó el sustrato preparado (residuos de alimentos + agua potable). La alimentación fue semi-continua y en una sola etapa, agregando $330 \mathrm{ml}$ de sustrato por día. Este volumen fue estimado mediante la ecuación 1, considerando un volumen $\left(V_{t}\right)$ de $5 \mathrm{~L}$ y un tiempo de retención hidráulica (TRH) de 15 días. La carga orgánica se determinó con la ecuación 2, indicada por Curry and Pillay (2012).

$Q=\frac{V_{t}}{T R H}$

$V C O=\frac{Q \times C S V}{V_{t}}$

En estas ecuaciones, $\mathrm{VCO}=$ Velocidad de carga orgánica $\left(\mathrm{kg} \mathrm{SV} / \mathrm{m}^{3} \mathrm{~d}\right) ; \mathrm{Q}=$ Flujo de alimentación $\left(\mathrm{m}^{3} / \mathrm{d}\right)$; $\mathrm{CSV}=$ Concentración de SV del sustrato en el influente $\left(\mathrm{kg} \mathrm{SV} / \mathrm{m}^{3}\right) ; \mathrm{V}_{\mathrm{t}}=$ Volumen total del digestor $\left(\mathrm{m}^{3}\right)$. La alimentación inicial en ambos digestores se realizó con una concentración de SV promedio de (7\%). A partir del día 50 se incrementó la concentración a $8 \%$ y en el día 100 a 9\%. La relación agua-residuos fue: concentración al 7\% de SV $=26.25 \mathrm{~g}$ de residuo $/ 303.75 \mathrm{ml}$ de agua; concentración al $8 \%$ de SV $=30.00 \mathrm{~g}$ de residuo / $300 \mathrm{ml}$ de agua; y concentración al 9\% de SV = 33.76 g de residuo / $296.24 \mathrm{ml}$ de agua. No se utilizaron sustancias alcalinas para neutralizar el pH del sustrato. Se determinó realizar el experimento de esta forma para verificar la adaptación de los sustratos a los inóculos.

Medición de parámetros

La concentración de metano $\left(\mathrm{CH}_{4}\right)$ en el biogás se determinó mediante un analizador de biogás por rayos infrarrojos Gasboard 3200-L. La medición de pH, temperatura y oxígeno disuelto se realizó con los sensores integrados al digestor. Para medir la producción de biogás, se desarrolló un sistema por desplazamiento de agua (ver Figura 2). Este consta de un recipiente de plástico claro, hermético, con capacidad para 2 L. Tiene 
dos tomas: una superior para el ingreso del biogás proveniente del biodigestor y otra inferior para la medición del líquido desplazado. Ésta última está conectada a una probeta de vidrio Pyrex de $250 \mathrm{ml}$. Para la medición, se agregaron $1.7 \mathrm{~L}$ de agua al recipiente y se conectó la toma superior al digestor. Durante 150 días se observó en la probeta la cantidad de agua desplazada por el biogás y se anotó este dato en un registro. Este procedimiento se realizó una vez por día.

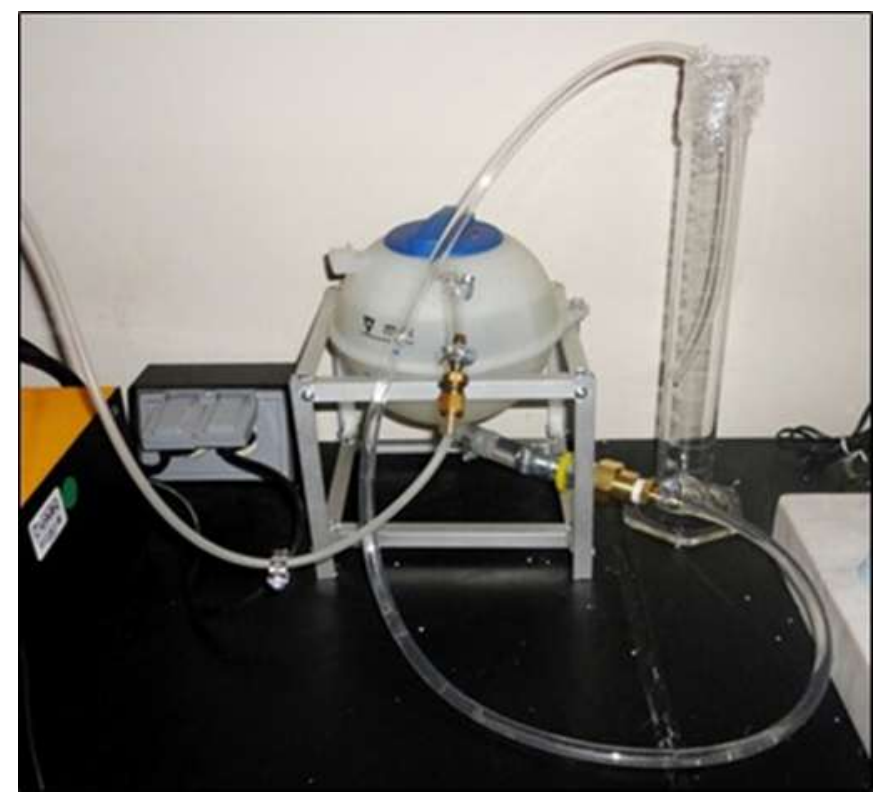

Fig. 2: Equipo de medición de biogás

\section{RESULTADOS Y DISCUSIÓN}

Los resultados se ordenan y discuten en tres subsecciones: i) la caracterización del inóculo; la caracterización de la materia prima fermentable; y (iii) el sistema de digestión

\section{Caracterización del inóculo}

Los resultados de la caracterización y los métodos analíticos empleados se presentan en la Tabla 3. El inóculo 1 (industria láctea) presentó características floculentas mientras que el inóculo 2 (industria cervecera) presentó características biogranulares. Esto se debe a que el primero proviene de un digestor tipo Laguna Anaerobia mientras que el segundo se obtuvo de un digestor tipo UASB.

La relación STVIST es una medida indirecta del grado de actividad biológica del inóculo. Liu et al., (2016) indican que el contenido orgánico típico para los lodos de plantas de tratamiento de aguas residuales (PTAR) se encuentra en el rango de $60 \%$ a $80 \%$, y que bajos contenidos orgánicos en los lodos conduce a un menor rendimiento en la producción de biogás. Los inóculos de este estudio estuvieron un 13\% por debajo del límite inferior recomendado, en parte debido a que los digestores no tratan agua residual municipal exclusivamente.

Tabla 3: Análisis físico-químicos de los inóculos

\begin{tabular}{|l|c|c|}
\hline \multicolumn{1}{|c|}{ Parámetro } & Inóculo 1 & Inóculo 2 \\
\hline $\mathrm{pH}$ & 7.06 & 8.62 \\
\hline Sólidos Volátiles \% & 51.62 & 52.03 \\
\hline Sólidos Totales (mg/L) & 2005 & 3825 \\
\hline Sólidos Totales Volátiles (mg/L) & 1035 & 1990 \\
\hline Sólidos Totales Fijos (mg/L) & 970 & 1835 \\
\hline Demanda Química de Oxígeno (mg/L) & 31755 & 41580 \\
\hline Relación C/N & 8.10 & 10.09 \\
\hline
\end{tabular}


Los lodos de las PTAR tiene baja relación C/N, generalmente andan en un rango del 6 al 9, que inciden negativamente en la eficiencia de la digestión anaerobia (Liu et al., 2016). La relación C/N del inóculo 2 es superior un $11 \%$ al límite superior señalado, mientras que el inóculo 1 se encuentra en el rango. Los valores de $\mathrm{C} / \mathrm{N}$ de los lodos se compensaron con el alto contenido orgánico y altas proporciones de $\mathrm{C} / \mathrm{N}$ del sustrato empleado en este estudio. El pH del inóculo 1 es neutro mientras que el inóculo 2 es alcalino. La diferencia en este comportamiento puede ser el tipo de residuo tratado. La planta láctea solo procesa residuos lácteos, que tienen un elevado nivel de acidez, mientras que la planta cervecera procesa aguas residuales de sus procesos y la ciudad.

\section{Caracterización y preparación de sustrato}

Se recolectaron $25.4 \mathrm{~kg}$ de residuos sólidos orgánicos, compuestos por $65.4 \%$ de vegetales; $2.1 \%$ cuero; $3 \%$ hueso; $5.4 \%$ carne; $12.8 \%$ arroz; $6.3 \%$ pan; $4 \%$ tortilla de maiz y $1 \%$ alimentos pre-cocidos. Los resultados de la caracterización fisico-química se muestran en la Tabla 4.

Tabla 4: Análisis físico-químicos del sustrato

\begin{tabular}{|l|c|}
\hline \multicolumn{1}{|c|}{ Parámetro } & Sustrato \\
\hline $\mathrm{pH}$ & 4.1 \\
\hline Densidad $(\mathrm{g} / \mathrm{L})$ & 1077.4 \\
\hline Humedad \% & 81.64 \\
\hline Cenizas \% & 5.65 \\
\hline Sólidos Volátiles \% & 94.35 \\
\hline Sólidos Totales (mg/L) & 189924 \\
\hline Sólidos Totales Volátiles $(\mathrm{mg} / \mathrm{L})$ & 179198 \\
\hline Sólidos Totales Fijos $(\mathrm{mg} / \mathrm{L})$ & 10726 \\
\hline Demanda Química de Oxígeno $(\mathrm{mg} / \mathrm{L})$ & 330540 \\
\hline Relación C/N & 20.56 \\
\hline
\end{tabular}

Para residuos de alimentos, se han reportado valores de pH de 4.2 (Zhai et al., 2015; Zhang et al., 2013) y 3.51 (Rincón-Ramirez et al., 2014). El pH de los residuos de este estudio es ácido (4.1). Esto es un indicador de que se tendrían que agregar agentes alcalinizantes al digestor para evitar la acidificación durante la operación. La relación $\mathrm{C} / \mathrm{N}$ en este estudio fue de 20.56 , cercano a otros valores de $\mathrm{C} / \mathrm{N}$ para residuos de alimentos de 24.5 (Zhang et al., 2013) y 21.4 (Ratanatamskul y Manpetch, 2016). El rango C/N recomendado para la adecuada operación de la digestión anaerobia es de 20 a 30, según Zhang et al., 2014 y Puyuelo et al., 2011. El sustrato de este estudio se encuentra dentro del rango, lo que indica que bajo estas condiciones existe un adecuado equilibrio de nutrientes requerido por las bacterias anaerobias para su crecimiento así como para mantener un ambiente estable. La relación de SV/ST fue de 0.94, lo que indica una alta biodegradabilidad del sustrato.

\section{Sistema de digestión}

Ambos inóculos tuvieron descensos durante los primeros 10 días de adaptación (ver Figura 3). Esto se debe a la actividad de las bacterias acidogénicas contenidas en los inóculos, las cuales consumen material orgánico y generan ácidos grasos volátiles. Esta actividad continúa hasta que la materia orgánica del inóculo comienza a escasear, en este punto empieza a estabilizarse el pH (Liu et al., 2016). En los primeros 7 días, el inóculo 1 presentó un descenso en el pH, de 7.06 a 6.73. A partir del día 8 hasta el día 10, el pH se mantuvo estable (6.68). El inóculo 2 presentó una disminución más lenta y se estabilizó en el séptimo día, en un valor de $\mathrm{pH}$ de 8.55. En ambos casos se aprecia que la capacidad de amortiguamiento no fue suficiente, debido a que los valores de $\mathrm{pH}$ se estabilizaron pero no incrementaron para el proceso de metanogénesis, como lo han reportado otros autores (Dai et al., 2016).

Las concentraciones de metano obtenidas en este estudio (ver Figura 4), no estuvieron en el rango de 6070\% reportado por otros autores (Dai et al., 2016; Li et al., 2014). En el primer caso (Li et al., 2014), aunque inóculo empleado presenta similitud a los sustratos de este estudio (VS/TS $=58.7 \pm 0.2 \% ; C / N=9.3 \pm 1.6$ ), el tipo de sustrato empleado (estiércol de pollo+rastrojo de maíz), el pH del sustrato $(7.34 \pm 0.13)$ y el porcentaje de sólidos totales (12\%) fueron diferentes a los de este estudio. En el segundo estudio (Dai et al., 2016), emplearon lodos activados, los cuales son caracterizados por tener una alta capacidad de amortiguamiento y ser capaces de tolerar co-sustratos con bajos valores de alcalinidad. 


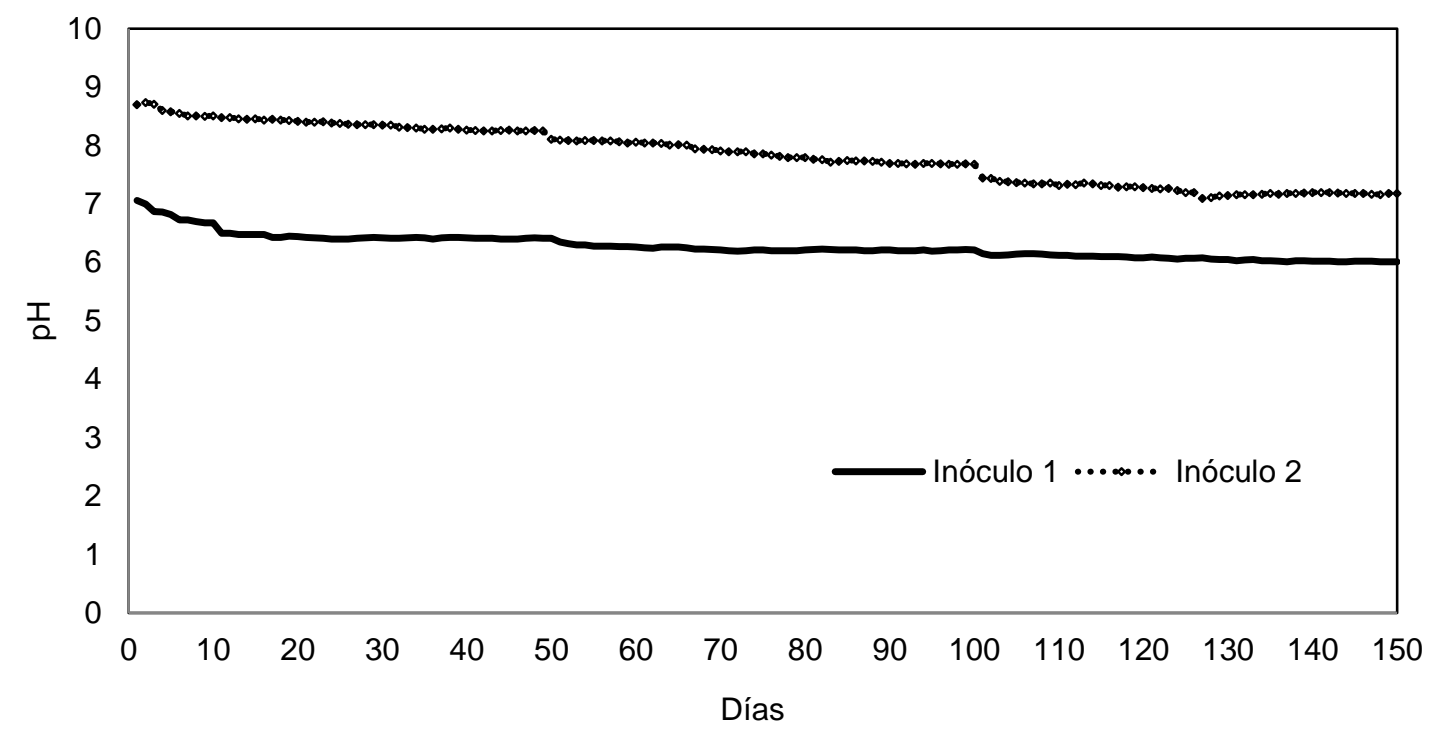

Fig. 3: Comportamiento del pH

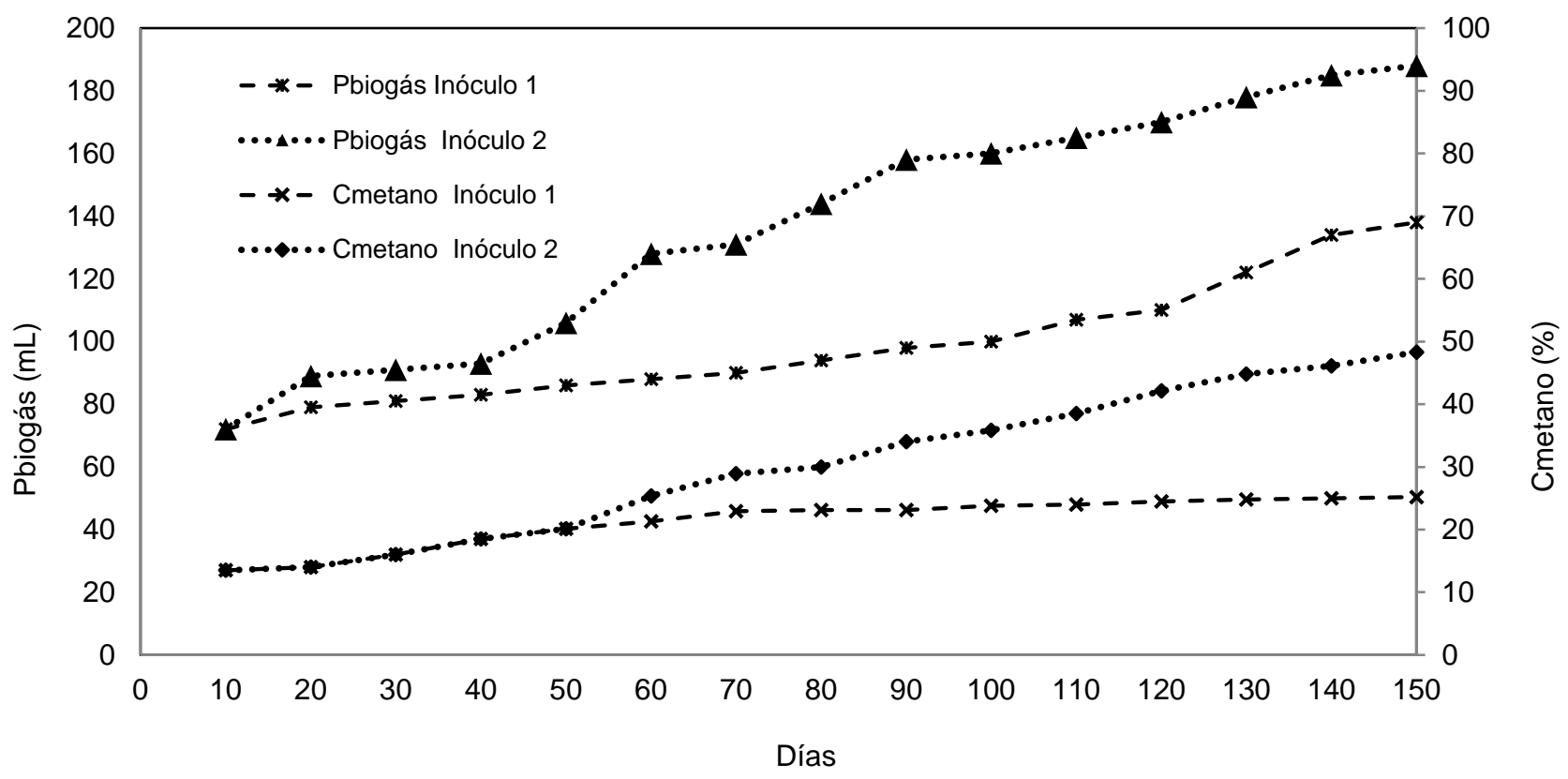

Fig. 4: Producción de biogás (Pbiogás) y concentración de metano (Cmetano)

La producción de biogás en este estudio no fue la óptima. Esto se debe a que no se agregaron sustancias alcalinizantes al digestor durante la operación y que al sustrato no se le agregaron sustancias para incrementar el amortiguamiento (Li et al., 2013), ajustar su pH o relación C/N (Li et al., 2014). El digestor que contiene el inóculo 1 presentó los resultados menos favorables en la producción de biogás y concentración de metano. Aunque la relación $\mathrm{C} / \mathrm{N}$ del sustrato se encontraba dentro de los límites recomendados, el inóculo presentó pH neutro y características de bajo contenido orgánico y baja relación $\mathrm{C} / \mathrm{N}$. Autores (Liu et al., 2016) han indicado que lodos con esas condiciones conducen a un bajo rendimiento en la producción de biogás. Las cargas orgánicas empleadas también influyeron en la producción de biogás. Si bien el sistema no se acidificó al incrementar las cargas, el pH se mantuvo entre 6.0 y 6.5 , que no es un rango óptimo para la operación de un digestor. Al incrementar la carga orgánica a 9\%, se incrementó la generación de biogás, pero no la concentración de metano. Se observa que del día 100 al día 150 el pH se mantuvo por debajo de 6.5, lo cual no es adecuado para el crecimiento de bacterias metanogénicas. Autores (Kwietniewska y Tys, 2014) indican una reducción en la tasa de crecimiento de los metanógenos por debajo de $\mathrm{pH} 6.6$.

En el día 150, el biogás en el digestor que contiene al inóculo 2 alcanzó una producción de $188 \mathrm{ml}$ y una concentración de metano 48.3\% (ver Figura 4). Esto representa un 36\% más de generación de biogás y una concentración superior en $92 \%$, respecto al inóculo 1. El inóculo 2 presentó características físico-químicas 
que le permitieron una estabilización más rápida. El pH alcalino le favoreció para compensar el sustrato ácido durante todo el proceso de digestión. Esto se reflejó en una mayor producción de biogás y concentración de metano a través del tiempo.

\section{CONCLUSIONES}

En el estudio de adaptación de dos inóculos a residuos de alimentos, sin el uso de agentes alcalinizantes, se comprobó que el inóculo con mayor relación $\mathrm{C} / \mathrm{N}(>10)$ presentó mejores niveles de pH y concentración de metano durante la operación del digestor. La falta de agentes alcalinizantes comprometió los niveles de $\mathrm{pH}$ y concentración de metano, aún con baja concentración de contenido orgánico (7\%). Si se aumenta el contenido orgánico a un sistema de digestión que opera con un pH por debajo de 6.5 , es posible que no se acidifique y presente incrementos en la generación de biogás. Sin embargo, la concentración de metano será baja.

\section{AGRADECIMIENTOS}

Los autores desean agradecer al Programa para el Desarrollo Profesional Docente-Tipo Superior (PRODEP) por el financiamiento otorgado a través del proyecto de Integración de Redes Temáticas de Colaboración Académica 2015.

\section{REFERENCIAS}

Aguilar-Virgen, Q., P. Taboada-González, y S. Ojeda-Benítez, Potential production of electricity from biogas generated in a sanitary landfill, Ing. E Investig., 31(3), 56-65 (2011)

Brambilla, M., F. Araldi, M. Marchesi, B. Bertazzoni, M. Zagni, y P. Navarotto, Monitoring of the startup phase of one continuous anaerobic digester at pilot scale level, doi:10.1016/j.biombioe.2011.11.009, Biomass Bioenergy, 36, 439-446 (2012)

Browne, J. D., y J. D. Murphy, The impact of increasing organic loading in two phase digestion of food waste, doi:10.1016/j.renene.2014.05.026, Renew. Energy, 71, 69-76 (2014)

Cervi, R., M. Esperancini, y O. Bueno, Viabilidad Económica de la Utilización de Biogás para la Conversión en Energía Eléctrica, doi:10.4067/S0718-07642011000400002, Inf. Tecnológica, 22(4), 3-14 (2011)

Cooney, M. J., K. Lewis, K. Harris, Q. Zhang, y T. Yan, Start up performance of biochar packed bed anaerobic digesters, doi:10.1016/j.jwpe.2014.12.004, J. Water Process Eng. 9, e7-e13 (2016)

Curry, N., y P. Pillay, Biogas prediction and design of a food waste to energy system for the urban environment, doi:10.1016/j.renene.2011.10.019, Renew. Energy 41, 200-209, (2012)

Dai, X., X. Li, D. Zhang, Y. Chen, y L. Dai, Simultaneous enhancement of methane production and methane content in biogas from waste activated sludge and perennial ryegrass anaerobic co-digestion: The effects of $\mathrm{pH}$ and C/N ratio, doi:10.1016/j.biortech.2016.05.100, Bioresour. Technol. 216, 323-330 (2016)

Fisgativa, H., A. Tremier, y P. Dabert, Characterizing the variability of food waste quality: A need for efficient valorisation through anaerobic digestion, doi:10.1016/j.wasman.2016.01.041, Waste Manag., 50, 264-274 (2016)

Ghanimeh, S., M. El Fadel, y P. Saikaly, Mixing effect on thermophilic anaerobic digestion of source-sorted organic fraction of municipal solid waste, doi:10.1016/j.biortech.2012.02.125, Bioresour. Technol. 117, 63-71 (2012)

Grimberg, S. J., D. Hilderbrandt, M. Kinnunen, y S. Rogers, Anaerobic digestion of food waste through the operation of a mesophilic two-phase pilot scale digester - Assessment of variable loadings on system performance, doi:10.1016/j.biortech.2014.09.001, Bioresour. Technol., 178, 226-229 (2015)

Hach Method 8000, Oxygen Demand Chemical, for water, wastewater and seawater, 425-434, Colorado, USA (2003)

Hach Method 10072, Nitrogen Total, High Range (10.0 to $150.0 \mathrm{mg} / \mathrm{L} \mathrm{N})$. TNT Persulfate Digestion Method, for water and wastewater, 391-399, Colorado, USA (2003) 
Hach Method 10128, Organic Carbon Total, High Range (20-700 mg/L C), for wastewater and industrial waters, 417-423, Colorado, USA (2003)

INEGI, Estadísticas a propósito del día nacional de la familia mexicana, (En línea: http://www.inegi.org.mx/saladeprensa/aproposito/2015/familia0.pdf, Acceso: 3 de marzo de 2015), Instituto Nacional de Estadística y Geografía, México (2015)

Kwietniewska, E., y J. Tys, Process characteristics, inhibition factors and methane yields of anaerobic digestion process, with particular focus on microalgal biomass fermentation, doi:10.1016/j.rser.2014.03.041, Renew. Sustain. Energy Rev. 34, 491-500 (2014)

Latif, M. A., C. M. Mehta, y D. J. Batstone, Low pH anaerobic digestion of waste activated sludge for enhanced phosphorous release, doi:10.1016/j.watres.2015.05.062, Water Res. 81, 288-293 (2015)

Li, Y., R. Zhang, X. Liu, C. Chen, X. Xiao, L. Feng, Y. He, y G. Liu, Evaluating Methane Production from Anaerobic Mono- and Co-digestion of Kitchen Waste, Corn Stover, and Chicken Manure, doi:10.1021/ef400117f, Energy Fuels, 27(4), 2085-2091 (2013)

Li, Y., R. Zhang, Y. He, C. Zhang, X. Liu, C. Chen, y G. Liu, Anaerobic co-digestion of chicken manure and corn stover in batch and continuously stirred tank reactor (CSTR), doi:10.1016/j.biortech.2014.01.054, Bioresour. Technol. 156, 342-347 (2014)

Liu, C., H. Li, Y. Zhang, y C. Liu, Improve biogas production from low-organic-content sludge through highsolids anaerobic co-digestion with food waste, doi:10.1016/j.biortech.2016.07.130, Bioresour. Technol., 219, 252-260 (2016)

Lohri, C. R., L. Rodić, y C. Zurbrügg, Feasibility assessment tool for urban anaerobic digestion in developing countries, doi:10.1016/j.jenvman.2013.04.028, J. Environ. Manage., 126, 122-131, (2013)

Montes-Carmona, M., Estudio técnico-económico de la digestión anaerobia conjunta de la fracción orgánica de los residuos sólidos urbanos y lodos de depuradora, Universidad Politécnica de Madrid, Madrid. (2008)

Niu, Q., T. Kobayashi, Y. Takemura, K. Kubota, y Y.-Y. Li, Evaluation of functional microbial community's difference in full-scale and lab-scale anaerobic digesters feeding with different organic solid waste: Effects of substrate and operation factors, doi:10.1016/j.biortech.2015.05.107, Bioresour. Technol., 193, 110-118 (2015)

Pandey, P. K., P. M. Ndegwa, J. R. Alldredge, M. Pitts, y M. L. Soupir, Modeling effects of granules on the start-up of anaerobic digestion of dairy wastewater with Langmuir and extended Freundlich equations, doi:10.1007/s00449-010-0406-x, Bioprocess Biosyst. Eng. 33(7), 833-845 (2010)

Puyuelo, B., S. Ponsá, T. Gea, y A. Sánchez, Determining $\mathrm{C} / \mathrm{N}$ ratios for typical organic wastes using biodegradable fractions, doi:10.1016/j.chemosphere.2011.07.014, Chemosphere, 85(4), 653-659 (2011)

Ratanatamskul, C., y P. Manpetch, Comparative assessment of prototype digester configuration for biogas recovery from anaerobic co-digestion of food waste and rain tree leaf as feedstock, doi:10.1016/j.ibiod.2016.05.008, Int. Biodeterior. Biodegrad., 113, 367-374 (2016)

Rincón Ramírez, M., N. Rincón Lizardo, J. Mata Álvarez y I. Chirinos, Biodegradability of prepared food waste under mesophilic and thermophilics conditions using a complete mix anaerobic reactor, Cienc. E Ing. Neogranadina, 24(1), 29-48 (2014)

SCFI Secretaría de Comercio y Fomento Industrial (México), NMX-AA-16-1984, Protección al ambiente Contaminación del suelo - Residuos sólidos municipales - Determinación de humedad, 1-2, Distrito Federal, (1992a)

SCFI Secretaría de Comercio y Fomento Industrial (México), NMX-AA-024-1984, Protección al ambiente Contaminación del suelo - Residuos sólidos municipales - Determinación de nitrógeno total, 1-4, Distrito Federal (1992b)

SCFI Secretaría de Comercio y Fomento Industrial (México), NMX-AA-25-1984, Protección al ambientecontaminación del suelo-residuos sólidos-Determinación del pH-método potenciométrico, 1-2, Distrito Federal (1992c) 
SCFI Secretaría de Comercio y Fomento Industrial (México), NMX-AA-030-SCFI-2001, Análisis de agua Determinación de la demanda química de oxígeno en aguas naturales, residuales y residuales tratadas Método de prueba, 1-23, Distrito Federal (2001a)

SCFI Secretaría de Comercio y Fomento Industrial (México), NMX-AA-034-SCFI-2001, Análisis de agua Determinación de sólidos y sales disueltas en aguas naturales, residuales y residuales tratadas - Método de prueba, 1-18, Distrito Federal (2001b)

SCFI Secretaría de Comercio y Fomento Industrial (México), NMX-AA-089/2-SCFI-2010, Protección al ambiente - Calidad del agua, 1-42, Distrito Federal (2010)

SEMARNAT Secretaria de Medio Ambiente y Recursos Naturales (México), NOM-021-RECNAT-2000, Especificaciones de fertilidad, salinidad y clasificación de suelos, estudio, muestreo y análisis, 1-19, Distrito Federal (2000)

Varnero, M., K. Galleguillos, D. Guerrero, y A. Suárez, Producción de Biogás y Enmiendas Orgánicas a Partir del Residuo Olivícola (Alperujo), doi:10.4067/S0718 - 07642014000500011, Inf. Tecnológica, 25(5), 73-78 (2014)

Yang, L., Y. Huang, M. Zhao, Z. Huang, H. Miao, Z. Xu, y W. Ruan, Enhancing biogas generation performance from food wastes by high-solids thermophilic anaerobic digestion: Effect of $\mathrm{pH}$ adjustment, doi:10.1016/j.ibiod.2015.09.005, Int. Biodeterior. Biodegrad. 105, 153-159 (2015)

Zhai, N., T. Zhang, D. Yin, G. Yang, X. Wang, G. Ren, y Y. Feng, Effect of initial pH on anaerobic codigestion of kitchen waste and cow manure, doi:10.1016/j.wasman.2014.12.027, Waste Manag., 38, 126$131(2015)$

Zhang, C., H. Su, y T. Tan, Batch and semi-continuous anaerobic digestion of food waste in a dual solidliquid system, doi:10.1016/j.biortech.2013.03.030, Bioresour. Technol., 145, 10-16 (2013)

Zhang, C., H. Su, J. Baeyens, y T. Tan, Reviewing the anaerobic digestion of food waste for biogas production, doi:10.1016/j.rser.2014.05.038, Renew. Sustain. Energy Rev. 38, 383-392 (2014) 